\title{
Predicting the incidence of brucellosis in Western Iran using Markov switching model
}

Maryam Mohammadian-Khoshnoud ${ }^{1}$, Majid Sadeghifar ${ }^{2^{*}} \mathbb{D}$, Zahra Cheraghi ${ }^{3,4}$ and Zahra Hosseinkhani ${ }^{5}$

\begin{abstract}
Objective: Brucellosis is a zoonosis almost chronic disease. Brucellosis bacteria can remain in the environment for a long time. Thus, climate irregularities could pave the way for the survival of the bacterium brucellosis. Brucellosis is more common in men 25 to 29 years of age, in the western provinces, and in the spring months. The aim of this study is to investigate the effect of climatic factors as well as predicting the incidence of brucellosis in Qazvin province using the Markov switching model (MSM). This study is a secondary study of data collected from 2010 to 2019 in Qazvin province. The data include brucellosis cases and climatic parameters. Two state MSM with time lags of 0, 1 and 2 was fitted to the data. The Bayesian information criterion (BIC) was used to evaluate the models.

Results: According to the BIC, the two-state MSM with a 1-month lag is a suitable model. The month, the averagewind-speed, the minimum-temperature have a positive effect on the number of brucellosis, the age and rainfall have a negative effect. The results show that the probability of an outbreak for the third month of 2019 is $0.30 \%$.
\end{abstract}

\section{Introduction}

Brucellosis is a zoonosis almost chronic disease which is transmitted by direct or indirect contact with infected animals or products [1]. B. melitensis is the most common and acute pathogen that can cause various symptoms such as sudden tremors, general body aches [2-4]. Despite a good health care system in Iran, brucellosis is still an important endemic disease. Iran ranks fourth in the world of the incidence of brucellosis [5-7]. According to the National Guidelines, epidemiological and clinical data of patients in Iran are recorded online in the health monitoring system. Patients with epidemiological and clinical signs of brucellosis, i.e. fever, myalgia, results of two laboratory tests are considered as cases. Laboratory tests include the Wright test ( $>1.8$ indicating infection) and the 2ME (Mercaptoethanol Brucella agglutination test).

*Correspondence: sadeghifar@basu.ac.ir

${ }^{2}$ Department of Statistics, Faculty of Science, Bu-Ali Sina University,

Hamadan, Iran

Full list of author information is available at the end of the article
In Iran, the incidence of brucellosis is reported to be between 50 and 500 per 100,000 people, often of the $B$. melitensis type and is known as a local disease. The incidence rate of brucellosis in Qazvin is 27.43 per 100,000 during 2010-2019 [8].

In epidemiology, a sudden increase in the incidence of a disease at a specific time or place is called an outbreak. In this study, the outbreak of the disease means a sudden increase in the disease in Qazvin. Climatic factors directly and indirectly affect the growth and reproduction dynamics of pets, sheep/goat human interactions, pathogen replication and population immunity affect brucellosis ecology [9-12]. Temperature changes may have a greater impact on the brucellosis epidemic than other climatic factors [13].

Despite the significant effect of climatic factors on brucellosis, these factors have been overlooked in most studies. The primary purpose of this study was to investigate the effect of climatic factors on the incidence of brucellosis. The second purpose of this study is to use MSM for prediction. A number of researchers have used the MSM in disease prediction [14] but so far the performance of this method has not been evaluated in brucellosis data.

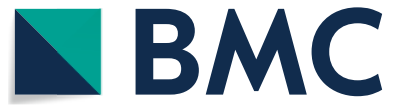

(c) The Author(s) 2021. This article is licensed under a Creative Commons Attribution 4.0 International License, which permits use, sharing, adaptation, distribution and reproduction in any medium or format, as long as you give appropriate credit to the original author(s) and the source, provide a link to the Creative Commons licence, and indicate if changes were made. The images or other third party material in this article are included in the article's Creative Commons licence, unless indicated otherwise in a credit line to the material. If material is not included in the article's Creative Commons licence and your intended use is not permitted by statutory regulation or exceeds the permitted use, you will need to obtain permission directly from the copyright holder. To view a copy of this licence, visit http://creativeco mmons.org/licenses/by/4.0/. The Creative Commons Public Domain Dedication waiver (http://creativecommons.org/publicdomain/ zero/1.0/) applies to the data made available in this article, unless otherwise stated in a credit line to the data. 


\section{Main text Method}

This study is a secondary study of data collected from April 2010 to March 2019 in Qazvin, which is extracted from the database of the Qazvin University of Medical Sciences and the meteorological system of the province [8]. No individual data were used. The available information was cumulative without mentioning personal information.

The response variable is the number of brucellosis cases. Month, rural-ratio, age, men-ratio, the ratio of contact with livestock, Non-pasteurized dairy and factors in the meteorological system include average-monthlytemperature, total-monthly-rainfall, average-wind-speed, maximum-monthly-temperature, minimum-monthlytemperature and wind-speed are considered as explanatory variables. The number of cases of brucellosis is very low in some months and if we consider daily or weekly cases, the number of cases will be zero on some times. Also, because brucellosis bacteria survive in the environment for a long time, considering monthly cases will help to better understand the factors affecting brucellosis.

In this study, the number of monthly cases of human brucellosis in Qazvin is a dependent variable $\left(\mathrm{Y}_{\mathrm{t}}\right)$. Independent variables $\left(\mathrm{X}_{\mathrm{t}} \mathrm{s}\right)$ with time lags of $0,-1$, and -2 were considered in two-states and three-states models. $\sigma_{s t}$ is the standard deviation of the error in the model.

MSM including time series $\left\{\mathrm{Y}_{\mathrm{t}}\right\}_{\mathrm{t}=1, \ldots, \mathrm{T}}$ and a sequence of related variables $\mathrm{x}_{1}, \ldots, \mathrm{x}_{\mathrm{T}}$ is introduced with the relation between $x_{t}$ and $Y_{t}$ as follows:

$$
Y_{t}=\boldsymbol{f}^{\left(s_{t}\right)}\left(\boldsymbol{x}_{\boldsymbol{t}}\right)+\boldsymbol{\sigma}_{\boldsymbol{s} t} \boldsymbol{\epsilon}_{\boldsymbol{t}}
$$

where $\boldsymbol{\epsilon}_{\boldsymbol{t}}$ has a standard normal distribution and $\mathrm{S}_{\mathrm{t}}$ is the state at time $t$ of a non-observable $\mathrm{N}$ state Markov chain.

According to the fitted MSM, beta is the estimation of the effect of each variable on the response in each state. $\mathrm{SE}$ is the standard deviation of beta and p-value shows the significance of each variable in the relevant state.

In two-state models, if we define state 1 as the disease outbreak period and 2 state as the non-outbreak period, the probability of an outbreak in period $t+1$ can be as follows [14]:

$$
\begin{aligned}
& P\left(s_{t+1}=1\right)=\frac{\left(1-p_{22}\right)}{\left(2-p_{11}-p_{22}\right)} \\
& P\left(s_{t+1}=2\right)=\frac{\left(1-p_{11}\right)}{\left(2-p_{11}-p_{22}\right)}
\end{aligned}
$$

A two-state MSM with switching all effects is considered. The data were analyzed through SPSS software version 26 and MSwM package of R software 3.6.3 [15].

\section{Results}

From 2010 to 2019, 3194 people were infected with brucellosis. Of these, the highest incidence related to the year 2015 with $512(16 \%)$, and the lowest incidence related to the year 2010 with 192 (6\%). In matching the seasons with the Gregorian months, spring is related to March, April and May, summer is related to June, July and August, fall is related to September, October, and November and finally, winter is related to December, January and February. Among seasons, the summer with 961 (30.1\%) and winter with 805 (25.2\%) have the highest number of infected, respectively. The highest number of patients is related to temperatures $26{ }^{\circ} \mathrm{C}(6.6 \%), 25{ }^{\circ} \mathrm{C}(6.4 \%)$. The highest number of infected people is related to zero rainfall of 444 cases $(13.9 \%)$ and the lowest number of patients is related to the average-monthly-rainfall of $17.8(0.2 \%)$ and $64.5(0.2 \%)$. The lowest number of patients is related to the averagewind-speed of 0.7 with 6 cases $(0.2 \%)$.

\section{Fitting MSM}

The MSM was fitted with two and three states and both models were fitted with $0,-1$, and -2 lags for climate variables. Temporal lag is defined as the time interval between climatic characteristics and the incidence of brucellosis. Based on a comparison between models, based on BIC, two-state MSM with a time lag of -1 is suitable. For this reason, only this model is offered to provide more results Fig. 1.

Age, month, rural-ratio, men-ratio, Non-pasteurized dairy, average-monthly-temperature, total-monthly-rainfall, average-wind-speed, maximum-monthly-temperature, Minimum-monthly-temperature, average-wind-speed, ratio of contact with livestock were recognized as significant variables (Table 1 ).

Autocorrelation and partial autocorrelation of residual and squared residual for model is confirmed lack of autocorrelation in the residual and the model seems to fit logically and there's no serial dependency on the residual.

Figure 2 shows the smoothed and filtered probabilities for state of one and two. Smoothed probabilities are used to determine peaks and depressions and 0.5 is determined as the cut-off value for 1 and 2 states. The filtered probabilities are calculated using the first observation up to $t$ and the smoothed probabilities are calculated using the total observations .

The Q-Q plot shows where the normality hypothesis is questionable for series. Transition probability matrix in MSM as follows:

$$
\left[\begin{array}{ll}
P_{11} & P_{12} \\
P_{21} & P_{22}
\end{array}\right]=\left[\begin{array}{cc}
P_{11} & 1-P_{11} \\
1-P_{22} & P_{22}
\end{array}\right]=\left[\begin{array}{ll}
0.72 & 0.28 \\
0.65 & 0.35
\end{array}\right]
$$

where the probability of non-outbreak state in both $t$ and $t+1$ periods is 0.72 , the probability of changing series 


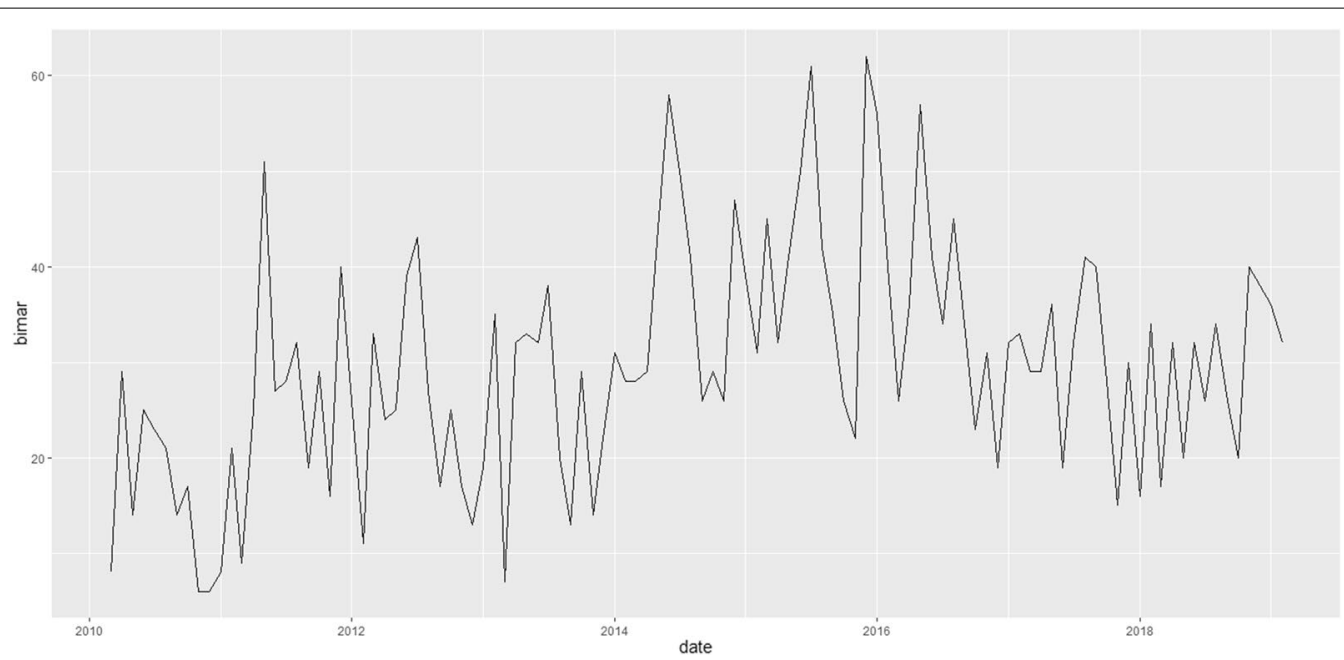

Fig. 1 The monthly trend chart for the number of brucellosis cases from 2010 to 2018

Table 1 The fit of the two-state markov switching model with time lags of $0,-1,-2$

\begin{tabular}{|c|c|c|c|c|c|c|c|c|c|}
\hline \multirow[t]{3}{*}{ Variables (state) } & \multicolumn{9}{|c|}{ MSM with two states } \\
\hline & \multicolumn{3}{|l|}{ Lag 0} & \multicolumn{3}{|l|}{ Lag - 1} & \multicolumn{3}{|l|}{ Lag - 2} \\
\hline & B & SE & p-value & B & SE & $p$-value & B & SE & p-value \\
\hline Intercept (1) & 3.274 & 3.073 & 0.287 & 9.981 & 11.531 & 0.387 & 33.426 & 11.879 & 0.005 \\
\hline Intercept (2) & 10.01 & 11.628 & 0.389 & 3.254 & 3.047 & 0.286 & -2.162 & 14.711 & 0.883 \\
\hline Age (1) & -0.152 & 0.016 & 0 & -0.116 & 0.118 & 0.326 & -0.25 & 0.059 & 0 \\
\hline Age (2) & -0.116 & 0.118 & 0.327 & -0.152 & 0.016 & 0 & 0.499 & 0.224 & 0.026 \\
\hline Month (1) & 1.618 & 0.108 & 0 & 0.817 & 0.371 & 0.028 & 1.164 & 0.408 & 0.004 \\
\hline Month (2) & 0.816 & 0.371 & 0.028 & 1.618 & 0.108 & 0 & -0.045 & 0.585 & 0.939 \\
\hline Rural ratio (1) & 3.172 & 0.113 & 0 & -0.287 & 0.389 & 0.461 & 2.666 & 0.513 & 0 \\
\hline Rural ratio (2) & -0.287 & 0.389 & 0.461 & 3.173 & 0.113 & 0 & 0.164 & 0.365 & 0.653 \\
\hline Men ratio (1) & 2.92 & 0.079 & 0 & -3.009 & 0.665 & 0 & -3.013 & 0.608 & 0 \\
\hline Men ratio (2) & -3.012 & 0.667 & 0 & 2.928 & 0.1 & 0 & 1.412 & 1.517 & 0.352 \\
\hline Non-pasteurized dairy (1) & -0.57 & 0.07 & 0 & 0.569 & 0.229 & 0.013 & 1.056 & 0.296 & 0 \\
\hline Non-pasteurized dairy (2) & 0.57 & 0.229 & 0.0127 & -0.571 & 0.069 & 0 & -0.273 & 0.23 & 0.235 \\
\hline Average monthly temperature (1) & -4.223 & 0.135 & 0 & 0.241 & 0.82 & 0.769 & 0.935 & 0.859 & 0.276 \\
\hline Average monthly temperature (2) & 0.239 & 0.852 & 0.779 & -4.229 & 0.142 & 0 & -2.546 & 1.017 & 0.012 \\
\hline Total monthly rainfall (1) & -0.038 & 0.015 & 0.012 & -0.034 & 0.041 & 0.405 & -0.242 & 0.048 & 0 \\
\hline Total monthly rainfall (2) & -0.034 & 0.041 & 0.405 & -0.038 & 0.015 & 0.011 & 0.009 & 0.053 & 0.85 \\
\hline Average wind speed (1) & 1.509 & 0.214 & 0 & 19.024 & 2.848 & 0 & 18.097 & 3.285 & 0 \\
\hline Average wind speed (2) & 19.017 & 2.869 & 0 & 1.533 & 0.185 & 0 & 5.163 & 3.336 & 0.122 \\
\hline Maximum monthly temperature (1) & 1.717 & 0.119 & 0 & -0.177 & 0.567 & 0.754 & -1.377 & 0.597 & 0.021 \\
\hline Maximum monthly temperature (2) & -0.176 & 0.585 & 0.763 & 1.718 & 0.118 & 0 & 0.722 & 0.629 & 0.251 \\
\hline Minimum monthly temperature (1) & 3.203 & 0.096 & 0 & 0.231 & 0.408 & 0.572 & 0.345 & 0.403 & 0.393 \\
\hline Minimum monthly temperature (2) & 0.231 & 0.417 & 0.579 & 3.207 & 0.101 & 0 & 2.289 & 0.599 & 0 \\
\hline Wind speed (1) & 0.944 & 0.072 & 0 & -0.698 & 0.301 & 0.02 & -0.433 & 0.25 & 0.083 \\
\hline Wind speed (2) & -0.699 & 0.302 & 0.02 & 0.944 & 0.072 & 0 & 0.469 & 0.288 & 0.103 \\
\hline Ratio of contact with livestock (1) & -0.387 & 0.059 & 0 & 0.904 & 0.28 & 0.001 & 0.283 & 0.221 & 0.2 \\
\hline Ratio of contact with livestock (2) & 0.904 & 0.28 & 0.001 & -0.387 & 0.059 & 0 & 1.212 & 0.561 & 0.031 \\
\hline
\end{tabular}



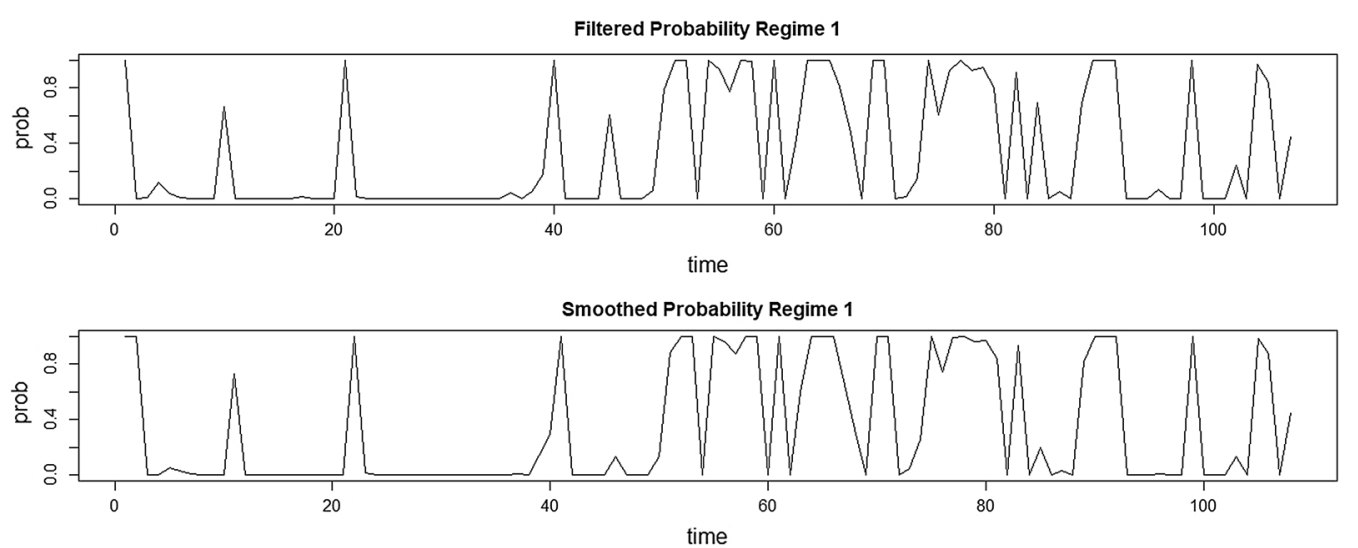

Fig. 2 Probability of smoothed and filtered states for state of one and two

from non-outbreak state in period $t$ to outbreak state in period $t+1$ is 0.28 and the probability of the series changing from the outbreak state in period $t$ to non-outbreak state in period $t+1$ is 0.65 . When we are in a nonoutbreak state (0.72), the process tends to stay the same state and the process is transferred to the outbreak state with a probability of 0.28 .

The probability of an outbreak in $t+1$ is as follows:

$$
\begin{aligned}
& P\left[S_{t+1}=1\right]=\frac{1-0.35}{2-0.72-0.35}=0.70 \\
& P\left[S_{t+1}=2\right]=0.30
\end{aligned}
$$

Since the data is up to the second month of 2019, the probability of an outbreak for the third month of 2019 ( 1 month later) is very low and is equal to $0.30 \%$.

The biggest difference between the coefficients of the variables in two states is related to the average-windspeed. Therefore, the average-wind-speed is the most important factor in incidence brucellosis.

Month, average-wind-speed and minimum-temperature coefficients are positive which indicate a positive effect on the number of brucellosis. The age and totalmonthly-rainfall coefficients are negative, indicating a negative effect on the number of brucellosis.

The temporal changes of the observed cases of brucellosis and the values estimated by the MSM are illustrated in Additional file 1: Figure S1. The model has a relatively good performance in identifying peaks incidence of brucellosis.

\section{Discussion}

The highest incidence of brucellosis is related to 2015 with 512 cases (16\%). The average wind speed was 1.89 . The incidence is the highest at zero total-monthly-rainfall. Total-monthly-rainfall was 0 at 444 days (13.9\%), which includes most days of study. The minimum-temperature was -1 and the maximum-temperature was $30{ }^{\circ} \mathrm{C}$. The mean age of the patients was about 38 years.

There is no clear pattern in the number of cases of brucellosis in the 8 years studied and fluctuations in the incidence of this disease can be seen with three peaks 2015 December, July 2015, June 2014. These results are inconsistent with the results of Lee's study. In the Lee's study, the incidence of human brucellosis in South Korea peaked in September 2006 and has dropped dramatically which indicates effective eradication [16]. In Rafiemanesh's study, the incidence of brucellosis decreased from 2007 to 2016 which indicates an increase in the coverage of prevention programs, especially livestock vaccination [17]. These results are inconsistent with the results of the present study.

In the 2010 year, the lowest number of cases has been reported, followed by an upward trend until 2011. The reason for the rising trend of the disease from 2010 to 2011 may be related to the improvement of the data registration in the country's health system. This result is consistent with Hashtarkhani's study [18]. From 2014 to 2017, there is an upward trend in the number of brucellosis cases which is inconsistent with Hashtarkhani's study. In the study of Hashtarkhani after 1990, we see a decreasing trend in the incidence of the disease [18]. The results of the study show that there are the highest number of infected people in summer and winter seasons. These results are consistent with the results of the Tapak's study. The results of the Tapak's study show that hot summers and cold winters make the disease less common while climate moderation in these seasons exacerbates the disease [19]. Therefore, the temperate climate of these seasons in Qazvin increases the number of patients with brucellosis. Model fit results indicate the negative effect of age and 
total-monthly-rainfall on the number of brucellosis. This result is consistent with the results of Entezari's study. The results of the Entezari's study indicate a negative relationship between rainfall and brucellosis. In fact, as the rainfall decreases, the number of infected people increases [20].

In zenoses, changes in climatic factors naturally affect the contamination rate and dynamics of animal hosts as well as human exposure to infected animals [21].

High levels of evaporation and sun exposure cause drought and limit the germination of the plant, while dry environments may cause human skin dryness and cracked skin and increase the risk [13].

Comparing the coefficients of explanatory variables in two state, the average-wind-speed is the most important factor in incidence brucellosis. This result is consistent with the results of Ahmadkhani's study. The results of Ahmadkhani's study indicate a positive correlation between wind-speed, temperature, greenness and incidence of brucellosis [22]. The results of the present study are inconsistent with those of Tapak. According to the Tapak's study, the wind at high speeds reduces the disease. This is because the bacterium has a shorter lifespan in the air.

The mean age of the patients was about 38 years. This result has been confirmed in other studies [23, 24]. The results of this study indicate that $\mathrm{P}_{11}$ and $\mathrm{P}_{22}$ are larger than $\mathrm{P}_{21}$ and $\mathrm{P}_{12}$, respectively. In other words, states do not tend to change. That is, when we are in a non-outbreak state, the process tends to remain the same state. Also, $\mathrm{P}_{21}$ is higher than $\mathrm{P}_{12}$, which indicates that prolonged periods of non-outbreak lead to a reduction in the probability of outbreak during the year.

As the country's health progresses in many areas, the incidence of brucellosis is expected to decline. However, the results of the present study indicate a sharp increase in the disease between 2014 and 2017, which requires a lot of health attention in Qazvin province. The necessary learning for high-risk age and occupational groups and not consuming unpasteurized dairy products and not having contact with suspicious animals and cooperating with livestock vaccination should be on the agenda of the region's health institutions.

\section{Conclusion}

The MSM can be used to detect factors related to the incidence of brucellosis as well as to predict the incidence of brucellosis. Most climatic parameters were effective in incidence the disease, and the most influential factor was the average-wind-speed. The probability of disease outbreak in the third month of 2019 was predicted to be $0.30 \%$.

\section{Limitation}

One of the limitations of this study is the limited period of the time series data and lack of daily information. Another limitation is the lack of comparison between different time series models.

\section{Supplementary Information}

The online version contains supplementary material available at https://doi. org/10.1186/s13104-020-05415-5.

Additional file 1. Figure S1: Prediction values obtained using Markov switching model along with the observed values.

Abbreviation

MSM: Markov switching model.

\section{Acknowledgements}

We would like to thank the staffs of the Department of Zoonotic Diseases at the Center for Communicable Disease Control, Ministry of Health and Medical Education of Iran (MOHME). Moreover, we thank the Vice-Chancellor of Research and Technology of Hamadan University of Medical Sciences.

\section{Authors' contributions}

Conceptualization: MMKh, MS, ZCh, ZH. Data curation: ZCh, ZH. Formal analysis: MMKh. Funding acquisition: ZCh. Methodology: MMKh, MS. Writingoriginal draft: MMKh, MS. Writing —review and editing: MMKh, MS, ZCh, ZH. All authors read and approved the final manuscript.

\section{Funding}

This study (980217943, IR.UMSHA.REC.1398.085) was funded by the Vice-Chancellor of Research and Technology of Hamadan University of Medical Sciences. The funders had no role in study design, data collection, and analysis, decision to publish, or preparation of the manuscript.

\section{Availability of data and materials}

The dataset used and/or analysed during the current study are available from the Zahra Hosseinkhani on reasonable request.

\section{Ethics approval and consent to participate}

Not applicable.

Consent for publication

Not applicable.

\section{Competing interests}

We declare that we have no competing interests.

\begin{abstract}
Author details
${ }^{1}$ Department of Biostatistics, School of Public Health, Hamadan University of Medical Sciences, Hamadan, Iran. ${ }^{2}$ Department of Statistics, Faculty of Science, Bu-Ali Sina University, Hamadan, Iran. ${ }^{3}$ Department of Epidemiology, School of Public Health, Hamadan University of Medical Sciences, Hamadan, Iran. ${ }^{4}$ Modeling of Noncommunicable Diseases Research Center, Hamadan University of Medical Sciences, Hamadan, Iran. ${ }^{5}$ Metabolic Diseases Research Center, Research Institute for Prevention of Non-Communicable Diseases,

Qazvin University of Medical Sciences, Qazvin, Iran.
\end{abstract}

Received: 16 July 2020 Accepted: 7 December 2020

Published online: 01 March 2021

\section{References}

1. Corbel M. Brucellosis in humans and animals. Geneva: World Health Organization; 2006. 
2. Franco M, Mulder M, Gilman R, Smits H. Human brucellosis. Lancent Infect Dis. 2007;7(12):775-86.

3. Silva T, Costa E, Paixão T, Tsolis R, Santos R. Laboratory animal models for brucellosis research. J Biomed Biotechnol. 2011;2011:518323.

4. Zeinali M, Shirzadi M, Sharifian J. National quideline for Brucellosis control. Tehran: Ministry of Health and Medical Education; 2009. p. 10-7.

5. Haran M, Agarwal A, Kupfer Y, Seneviratne C, Chawla K, Tessler S. Brucellosis presenting as septic shock. BMJ Case Rep. 2011;2011.

6. Pappas G, Papadimitriou P, Akritidis N, Christou L, Tsianos E. The new global map of human brucellosis. Lancet Infect Dis. 2006;6(2):91-9.

7. Ramin B, MacPherson P. Human brucellosis. BMJ. 2010;341:C4545.

8. Bagheri H, Tapak L, Karami M, Hosseinkhani Z, Najari H, Karimi S, et al. Forecasting the monthly incidence rate of brucellosis in west of Iran using time series and data mining from 2010 to 2019. PLoS ONE. 2020;15(5):e0232910.

9. Rodriguez-Morales JA. Climate change, climate variability and brucellosis. Recent Pat Antiinfect Drug Discov. 2013;8(1):4-12.

10. Li Y, Li X, Liang S, Fang L, Cao W. Epidemiological features and risk factors associated with the spatial and temporal distribution of human brucellosis in China. BMC Infect Dis. 2013:13:547.

11. Yang Z, Li X, Shao Z, Ma W, Yuan X, Wu K, et al. Characteristics on spatial and temporal distribution as well as the driving effect of meteorological factors on brucellosis in Datong city, Shanxi province, 2005-2015. Zhonghua Liu Xing Bing Xue Za Zhi. 2018;39(9):1165-71.

12. Zhu H, Wang L, Lin D, Hong R, Ou J, Chen W, et al. Analysis on epidemiology and spatial-temporal clustering of human brucellosis in Fujian province, 2011-2016. Chin J Epidemiol. 2017:38(9):1212-7.

13. Liu K, Yang Z, Liang W, Guo T, Long Y, Shao Z. Effect of climatic factors on the seasonal fluctuation of human brucellosis in Yulin, northern China. BMC Public Health. 2020;20(1):506.

14. Ansari H, Mansournia M, Izadi S, Zeinali M, Mahmoodi M, HolakouieNaieni K. Predicting CCHF incidence and its related factors using time-series analysis in the southeast of Iran: comparison of SARIMA and Markov switching models. Epidemiol Infect. 2015;143(4):839-50.

15. Sanchez-Espigares J, Lpez-Moreno A. MSwM: Fitting Markov switching models. R package version. 2014;1.4.
16. Lee H, Her M, Levine M, Moore G. Time series analysis of human and bovine brucellosis in South Korea from 2005 to 2010. Prev Vet Med. 2013:110(2):190-7.

17. Rafiemanesh H, Alimohamadi Y, Aghdam S, Safarzadeh A, Shokri A, Zemestani A. Time series and trend analysis of brucellosis in Oskou county, East Azerbaijan: 2007-2016. Health Promot Perspect. 2019:9(4):285-90.

18. Hashtarkhani S, Akbari M, Jarahi L, Etminani K. Epidemiological characteristics and trend of incidence of Human brucellosis in Razavi Khorasan province. Med J Mashhad Univ Med Sci. 2015;58(9):531-8.

19. Tapak L, Shirmohammadi-Khorram N, Hamidi O, Maryanaji Z. Predicting the frequency of human brucellosis using climatic indices by three data mining techniques of radial basis function, multilayer perceptron and nearest Neighbor: a comparative study. IRJE. 2018;14(2):153-65.

20. Entezari M, Moradpour S, Amiri M. Spatial distribution and the impact of geographical factors on brucellosis in Chaharmahal and Bakhtiari Province, Iran. Int J Epidemiol Res. 2016;3(2):98-105.

21. Al-Talafhah A, Lafi S, Al-Tarazi Y. Epidemiology of ovine brucellosis in Awassi sheep in Northern Jordan. Prev Vet Med. 2003;60(4):297-306.

22. Ahmadkhani M, Alesheikh A. Space-time analysis of human brucellosis considering environmental factors in Iran. Asian Pac J Trop Dis. 2017;7(5):257-65.

23. Al-Tawfiq J, AbuKhamsin A. A 24-year study of the epidemiology of human brucellosis in a health-care system in Eastern Saudi Arabia. Infect Public Health. 2009;2(2):81-5.

24. Buzgan T, Karahocagil M, Irmak H, Baran A, Karsen H, Evirgen O, et al. Clinical manifestations and complications in 1028 cases of brucellosis: a retrospective evaluation and review of the literature. Int J Infect Dis. 2010;14(6):e469-78

\section{Publisher's Note}

Springer Nature remains neutral with regard to jurisdictional claims in published maps and institutional affiliations.
Ready to submit your research? Choose BMC and benefit from:

- fast, convenient online submission

- thorough peer review by experienced researchers in your field

- rapid publication on acceptance

- support for research data, including large and complex data types

- gold Open Access which fosters wider collaboration and increased citations

- maximum visibility for your research: over 100M website views per year

At $B M C$, research is always in progress.

Learn more biomedcentral.com/submissions 